\title{
SPONTANEOUS PNEUMOTHORAX, MASSIVE COLLAPSE, AND SUBCUTANEOUS EMPHYSEMA COMPLICATING ASTHMA
}

BY

\author{
C. ELAINE FIELD, M.D., M.R.C.P.
}

\section{E.M.S. Base Hospital, Hemel Hempstead (Great Ormond Street)}

Subcutaneous emphysema or spontaneous pneumothorax in association with asthma is a rare complication and the combined condition is even more rare, only one case report being found in the literature. For these three conditions to be present in association with massive collapse of the lung is, in all probability, unique.
Subcutaneous emphysema complicating asthma. Rosenberg and Rosenberg (1938) report the condition in a child aged three years and could only find seventeen similar cases in the literature. These occurred in the age period 3 to 38 years, eleven cases occurring in the first two decades. The duration of the emphysema was two days to three weeks, and although several were very ill there were no

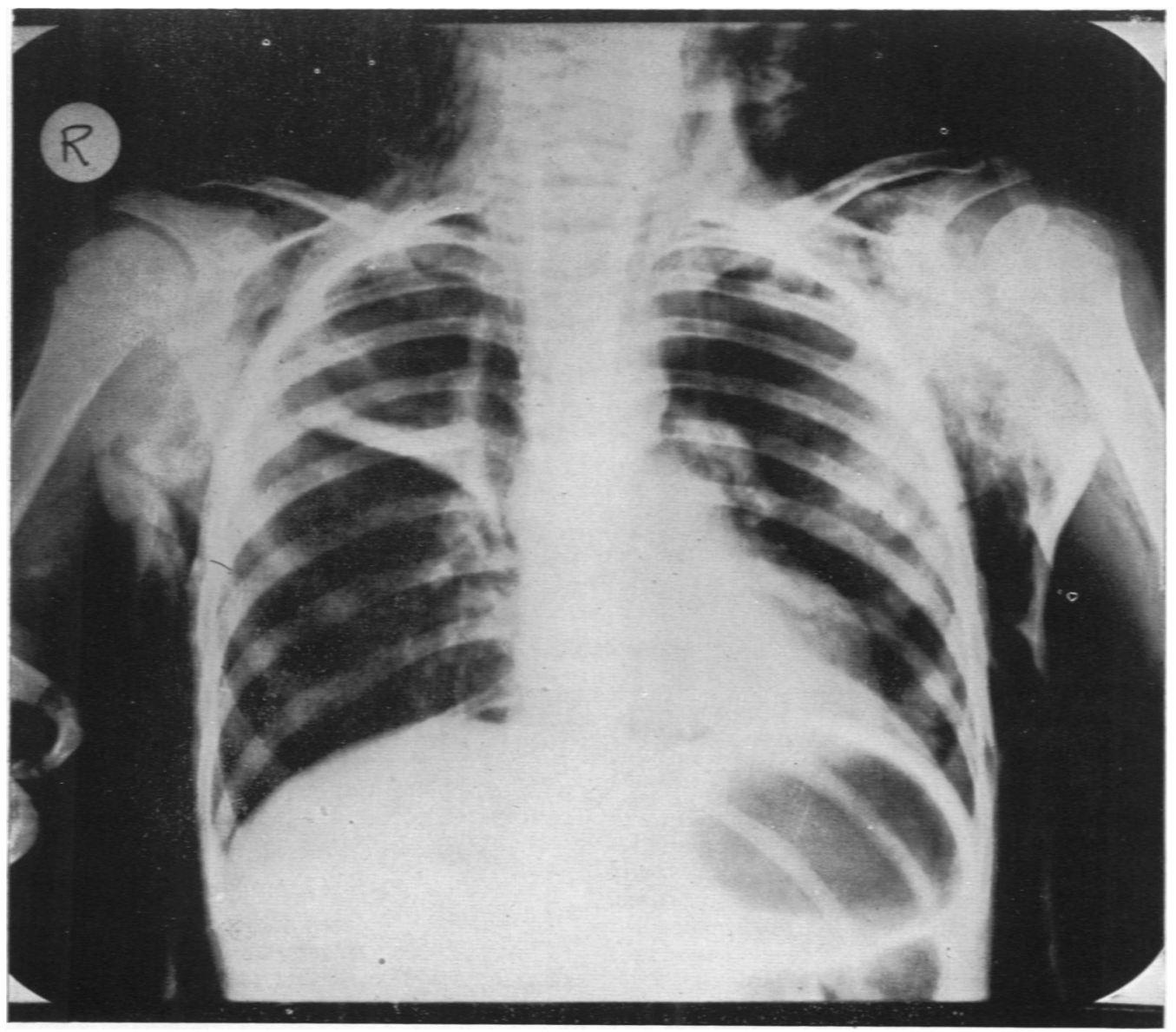

FIG. 1.-Second day of first asthmatic attack showing subcutaneous emphysema; displacement of heart to the left with collapse of left lower lobe; V-shaped shadow in right upper lobe probably inflammatory. 
deaths and no recurrences. Macklin (1939) produced the condition in cats by distending the lungs with air through a catheter in a bronchus. It was seen on section that the alveoli had ruptured in several minute spots and the escaping air had tracked along the interstitial tissue of the pulmonary vessels to the hilum. In doing so it tends by pressure to occlude the vessels and cause circulatory embarrassment. From the hilum the air either tracked up to the neck and face, downwards to retro-peritoneal tissues and legs, across to the heart, or through into the pleural cavity producing a spontaneous pneumothorax. The latter may on the right side. He could find no other case report of this condition.

Massive collapse of the lung in association with asthma is a comparatively common occurrence, it is usually transient and can be accounted for by sticky secretion being held up in a narrowed spastic bronchus with absorption of air and consequent collapse in the part of lung supplied by that bronchus. As the attack passes off the bronchus dilates, the secretion becomes more fluid and is coughed up and the lung re-expands.

Spontaneous pneumothorax with massive collapse of the lung. Cummings (1935) reports a case in

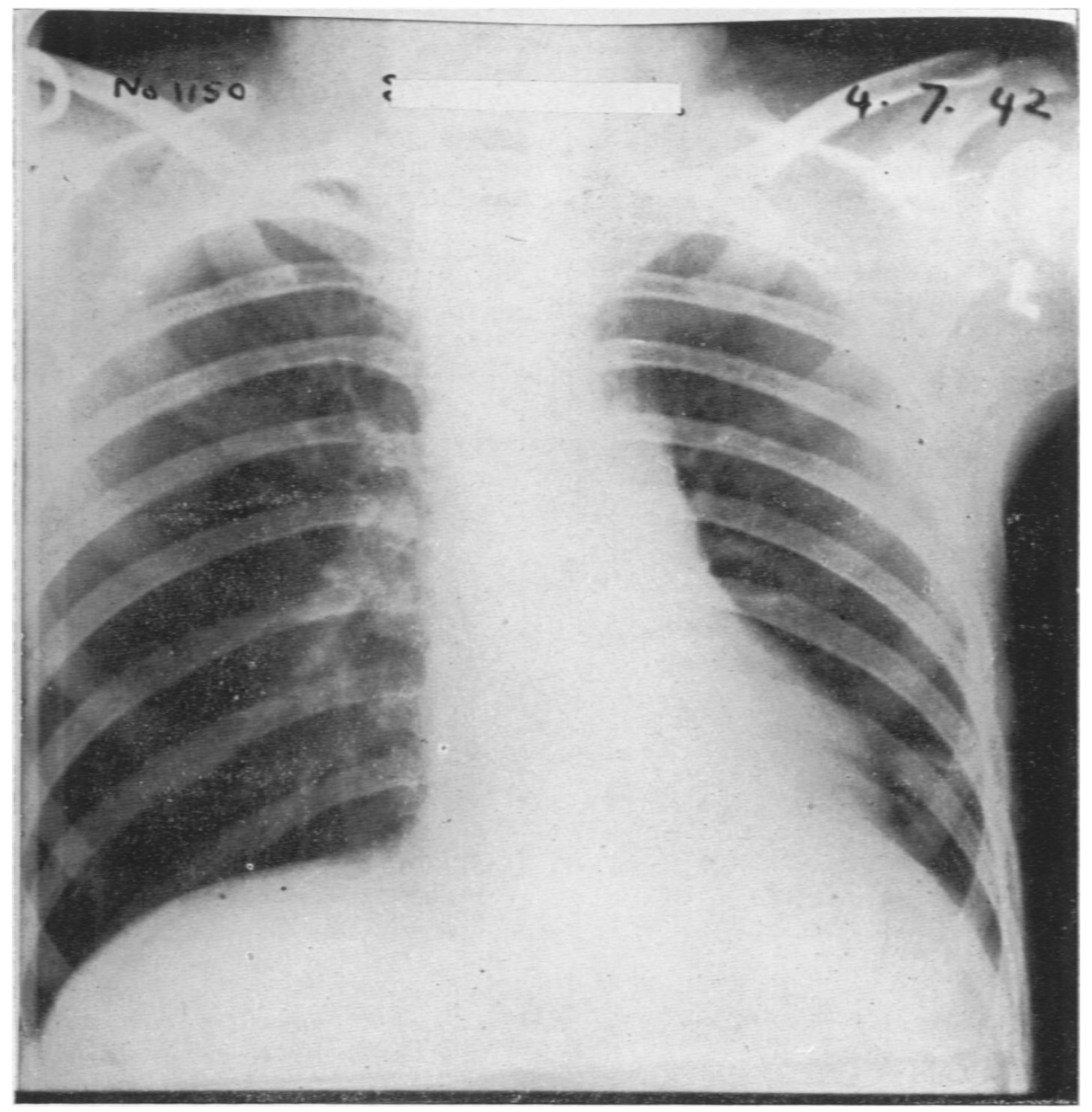

Fig. 2.-One week after first asthmatic attack. Subcutaneous emphysema subsided; collapse of left lower lobe persists.

bring about a cure by closing the holes in the ruptured alveoli.

Spontaneous pneumothorax complicating asthma is possibly a rarer occurrence than subcutaneous emphysema, but a more serious one. Castex and Mazzei (1938) review the literature of twelve cases. The age period (11 to 59 years) is higher than for subcutaneous emphysema and three died, giving a mortality of 25 per cent.

Subcutaneous emphysema and spontaneous pneumothorax in asthma. Elliott (1938) reports the condition in a woman aged 46 . Emphysema developed at the onset of the attack, and two days later partial pneumothorax was discovered by $\mathrm{x}$-ray examination a child aged nine months following pneumonia with complete recovery, but no report of this condition associated with asthma can be found.

\section{Case report}

A girl aged 4 years and 2 months was admitted to hospital as an emergency on June 28 in an attack of asthma. The mother stated that the child had developed a cold three days previously but had only been breathless and wheezy for one day. On the morning of the admission swelling of the neck was noticed for the first time. The child had suffered from severe asthmatic attacks every four to six 
weeks since ten months of age and earlier in the year had received a course of injections of mixed inhalants plus 20 per cent. pollens, as skin tests showed her sensitive to pollens.

Previous illnesses. She had pneumonia at 18 months with whooping cough, since when her asthma had been worse. There was no eczema in infancy.

FAMILY HISTORY. No one suffered from hay fever or asthma, but the mother had migraine.

Present state. On admission she looked ill, left hilar glands were enlarged. In the right upper zone there was a V-shaped shadow pointing towards the hilum.

TREATMENT. She was given adrenalin 2 minims and nepenthe 5 minims, and put in an oxygen tent. Air was aspirated from the pectoral region, but as this caused more distress than relief it was discontinued.

Progress. Although her respiration had risen to 47 a minute the next day, her general condition had improved and she was removed from the

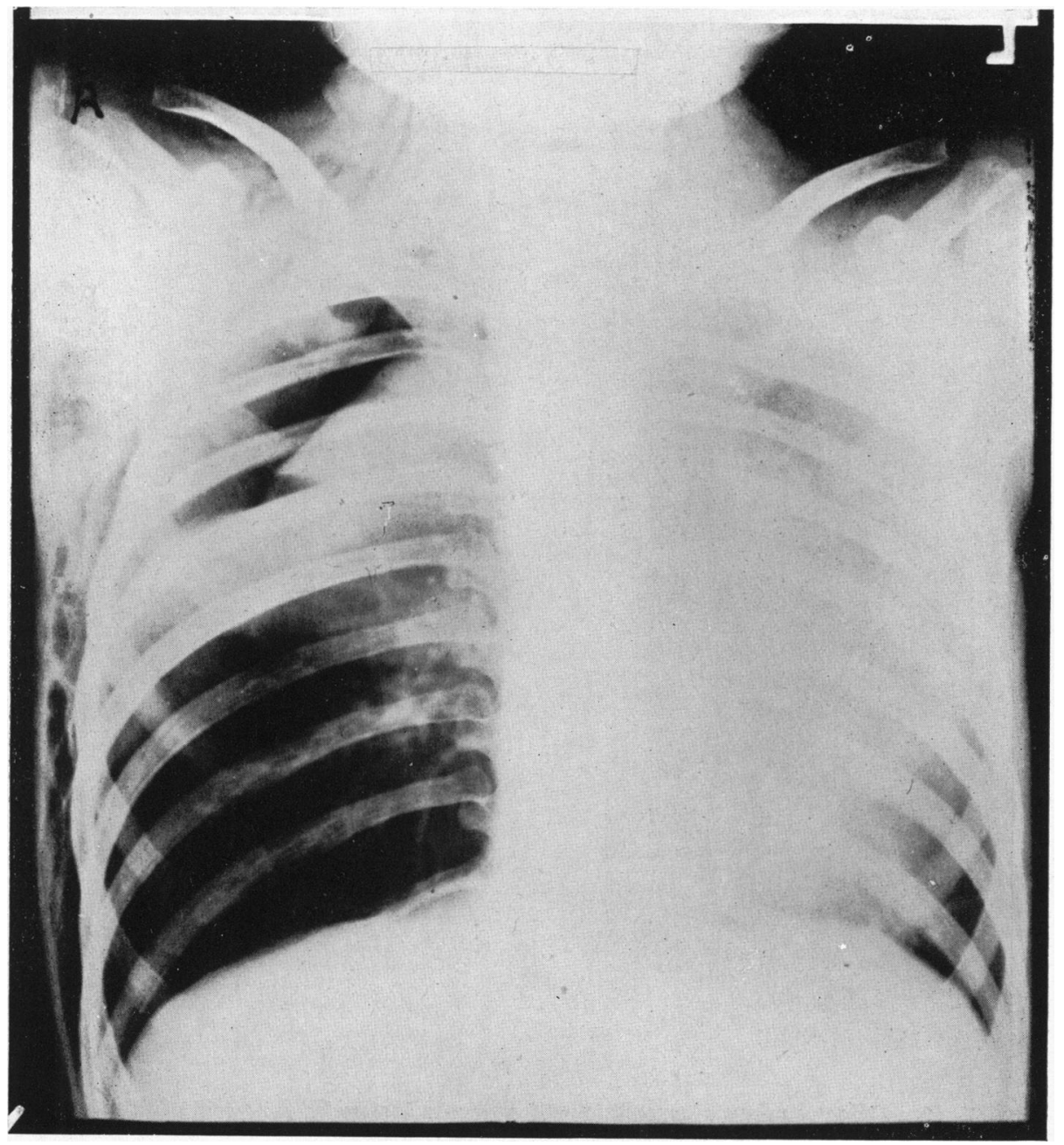

FIG. 3.-Second day of second asthmatic attack showing heart in left chest with massive collapse of left lung; localized collapse of right upper lobe with spontaneous pneumothorax.

was cyanosed and dyspnoeic, but not wheezing. Temperature was $99.8 \mathrm{~F}$., pulse 144 and respiration 34 per minute. There was subcutaneous emphysema extending around the neck, on the face, over the chest, abdomen and thighs. On examination of the chest the heart appeared to be central, the breath sounds were harsh and rhonchi heard over both lung fields, but subcutaneous emphysema prevented the detection of râles.

X-RAY OF CHEST (fig. 1) showed extensive subcutaneous emphysema, the heart was displaced to the left with a shadow behind the left border suggesting collapse of the left lower lobe. The oxygen tent. During the next twelve days the subcutaneous emphysema slowly subsided and completely disappeared and the child was transferred to the Base Hospital. Further investigations showed her tuberculin reaction (Mantoux 1/1000) was negative.

The adventitious signs in the chest disappeared, but the percussion note remained dull at the left base. X-ray examination of the chest on July 4 (fig. 2) shows the heart still displaced to the left with an opacity behind suggesting persistence of the left lower lobe collapse confirmed in the lateral x-ray. The right upper zone shadow had disappeared. 
She remained fairly well until July 10 when she developed a hard cough, was 'off colour' in the afternoon and refused her tea. The temperature was normal, but respirations had risen to 36 . On examination of the chest the forcible apex beat had moved to the left and was now in the mid-axillary line. The left side of the chest was dull to percussion with a poor air entry; on the right side, the percussion note was normal, but expiration was prolonged and scattered rhonchi were heard on both sides. By 8.30 p.m. she was much more dyspnoeic and examination of the chest now showed hyperresonance over the right lung. One hundred cubic centimetres of air was aspirated from the eighth right intercostal space behind, no more being
When seen at 9 a.m. the next morning (July 11) she was very restless, the chest signs showing no significant change. She was given another dose of nepenthe, 4 minims. At mid-day, after a good sleep, she suddenly sat up and said she was hungry, she looked very much better and ate a good meal, although still dyspnoeic. At this stage an x-ray picture of the chest was taken (fig. 3). It shows the heart displaced into the left chest, and practically no aeration of the left lung except at the costophrenic angle. In the upper part of the right chest there is a localized spontaneous pneumothorax producing a localized collapse of the adjacent lung.

In two days' time her dyspnoea had disappeared and the chest signs were returning to normal.

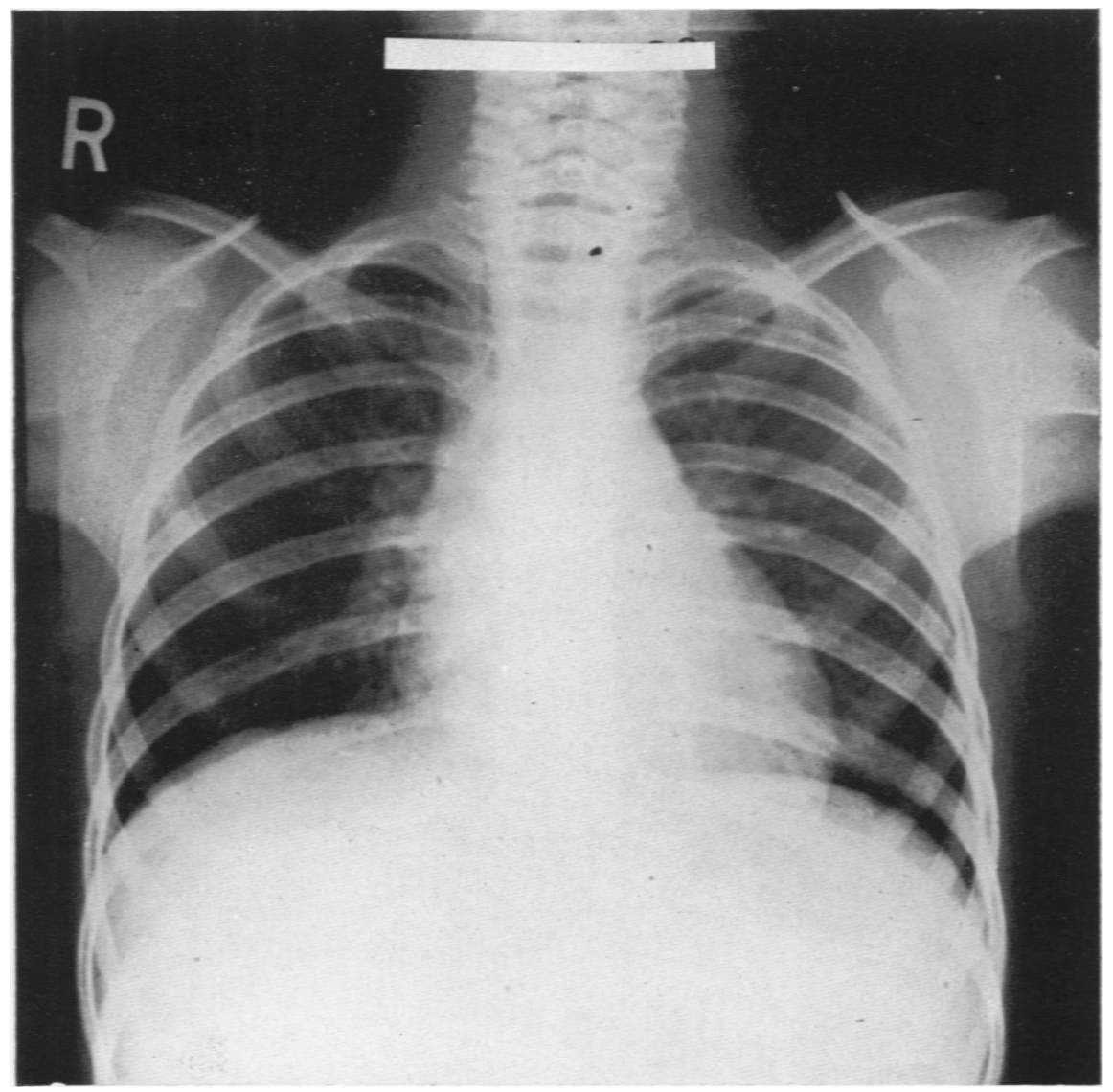

Fig. 4.-Nineteen days after second asthmatic attack showing a normal chest $x$-ray.

obtainable. This made the child worse, so she was placed in an oxygen tent. In spite of the lung findings the child appeared to be in a severe asthmatic attack, so she was given adrenalin hydrochlor. (1/1000) 10 minims (one minim a minute) and atropine sulphate, $1 / 100$ grain. This produced considerable relief. At midnight the condition was still serious, and the chest signs showed little change, the percussion note on the right side was more hyperresonant at the right apex and the breath sounds were very faint. Aspiration of air was repeated, this time in the second interspace anteriorly and 630 c.c. obtained. During this process the apex beat moved in an inch. She was now given nepenthe 4 minims by mouth and had a fair night in the oxygen tent.
On July 20 a further $\mathrm{x}$-ray showed the heart practically central and the left lung to be fully expanded. The localized right spontaneous pneumothorax was smaller. On July 28, x-ray examination of the chest was normal (fig. 4) and the child was discharged home on August 1. She had only had two mild attacks of asthma since and no recurrence of the subcutaneous emphysema, spontaneous pneumothorax or collapse.

\section{Discussion}

A possible explanation for the sequence of events occurring in this remarkable case is as follows. On June 25 a nasopharyngeal infection developed and spread to the right upper lobe of the lung 
producing a mild inflammation. Two days later an asthmatic attack occurred causing rupture- of alveoli in the inflammatory area of the right upper lobe. Air tracked along the interstitial tissue of the lung to the hilum, up the mediastinum to the neck, face, chest, abdomen and thighs. X-ray examination at this time suggests an associated collapse of the left lower lobe. The subcutaneous emphysema was slowly absorbed, but the collapsed left lower lobe persisted. On July 10 (fifteen days from the first symptom) a second attack of asthma developed resulting in accumulation of mucus in the left upper lobe bronchus producing sudden collapse of the left upper lobe. This catastrophe combined with the already collapsed left lower lobe produced a rapid shift of the heart and mediastinum to the left, resulting in rupture of recent adhesions in the right apper lobe. The recently sealed air leak was reopened, this time into the pleural cavity, producing a localized spontaneous pneumothorax.
Summary

A case is reported of a girl aged 4 years and 2 months who showed the combined features of asthma, subcutaneous emphysema, collapse of the left lung and spontaneous pneumothorax in the right chest, with recovery. This is probably a unique phenomenon.

Thanks are due to Dr. W. G. Wyllie for his helpful criticism and permission to publish this case.

\section{REFERENCES}

Castex, M. R., and Mazzei, E. S. (1938). Pr. méd., 46, 529.

Cummings, R. E. (1935). Arch. Pediat., 52, 623.

Elliott, R. W. (1938). Lancet, 1, 1104.

Escudero, L., and Adams, W. E. (1939). Arch. intern. Med., 63, 29.

Macklin, C. C. (1939). Ibid., 64, 913.

Rosenberg, L., and Rosenberg, J. (1938). Amer. J. med. Sci., 145, 682. 